\title{
Erratum to: Understanding Invasive Species in the Galapagos Islands From the Molecular to the Landscape
}

\author{
María de Lourdes Torres and Carlos F. Mena
}

\section{Erratum to:}

M. d. L. Torres, C. Mena (eds.), Understanding

Invasive Species in the Galapagos Islands, Social and Ecological Interactions in the Galapagos Islands, https://doi.org/10.1007/978-3-319-67177-2

This book was inadvertently published without the cover image credit "Courtesy of Kiyoko Gotanda" included in the copyright page. This has now been included in this revised version of the book. 